\title{
ЕДИНЫЙ СТАНДАРТ ОТЧЕТНОСТИ В ГОСТИНИЧНОЙ ИНДУСТРИИ USALI КАК ОСНОВА ОПТИМИЗАЦИИ СИСТЕМЫ ВНУТРЕННЕГО КОНТРОЛЯ
}

\author{
(c) 2021 Наумова Н.ю. \\ студент Департамента бизнес-аналитики \\ Финансовый университет при Правительстве Российской Федерации, Россия, Москва
}

(c) 2021 Лялькова Е. Е.

кандидат экономических наук, доцент, доцент Департамента бизнес-аналитики Факультета налогов, аудита и бизнес-анализа Финансовый университет при Правительстве Российской Федерации, Россия, Москва доцент кафедры «Бухгалтерского учета и налогообложения»

ФГБОУ ВО РЭУ им. Плеханова, Россия, Москва

E-mail:EELyalkova@fa.ru

Гостиничный бизнес представляет собой сложную, многокомпонентную конструктивную систему экономических отношений, которые охватывают оказание услуг по размещению гостей, формированию режимов питания и реализации ряда продуктов спортивно-оздоровительного сервиса и прочих услуг. В условиях роста отелям необходимо обеспечить финансовую устойчивость и независимость, и одним из факторов, определяющим устойчивое положение на динамичном рынке в условиях высокой конкуренции, является оперативность и качество операционной и финансовой информации, используемой для принятия управленческих решений. Также оперативность принятия решений помогает при нестабильных ситуациях в кризисных условиях пандемии.

The Uniform System of Accounts for the Lodging Industry (USALI) - система стандартов управленческой отчетности в гостиничной индустрии хорошо знакома международному бизнесу, и давно стала обязательной составной частью бизнес-культуры. Сегодня USALI - это наиболее часто используемый стандарт ведения управленческой отчетности, понятный гостиничным специалистам во всем мире и в России. Первая версия стандарта была опубликована в 1926 г. и с тех пор постоянно изменяется и развивается вслед за изменениями бизнес-среды: состав объектов гостеприимства, развитие применяемых технологий, совершенствование стандартов оказания услуг, GAAP (USA) и пр. На сегодняшний день действующая 11-я редакция стандартов, которая была опубликована в 2014 году. Официальными авторами действующей редакции являются общественные объединения Financial
Management Committee of the American Hotel and Lodging Association (AH\&LA) и Hospitality Financial and Technology Professionals (HFTP).

USALI была создана для анализа деятельности отеля. Стандарты USALI получили широкое распространение по всему миру благодаря простоте внедрения и применения, которая удачно сочетается с учетом особенностей гостиничного сектора. USALI описывает принципы планирования и контроля основных показателей деятельности, а также для сравнения показателей работы различных отелей между собой. USALI это стандарты, разработанные специалистами с многолетним гостиничным опытом и ориентированные на все гостиничные предприятия - от мини-отеля до огромного курортного комплекca.

В целях оптимизации системы внутреннего контроля необходимо выявить ключевые точки повышенного риска финансовых потерь, разработать и экономически обосновать проект мероприятий, чтобы минимизировать риски, а для максимального увеличения доходов, необходимо правильно выстроить систему локальных операционных процедур гостиницы.

В крупных гостиницах, как правило, есть внутренний аудитор, который проверяет первичную документацию, анализирует финансовые данные и гостиничные показатели при различных условиях. Также аудитор занимается совершенствованием контроля по средствам введения или изменения локальных операционных процедур.

Локальные операционные процедуры - это прописанные правила действий персонала на всех центрах финансовой ответственности, при 
контактах с гостями, для предоставления отчетности и для ведения кассовой дисциплины и т.д. Локальные операционные процедуры являются важным инструментом в управленческом учете для усиления контроля корректности отражения финансовых данных.

Система внутреннего контроля в гостинице охватывает все службы и функциональные подразделения. Одной из целей системы внутреннего контроля является исключение из деятельности двух типов риска - риск неоплаты услуг и риск потери выручки.

На рисунке 1 представлены повышенные точки риска предприятии размещения. Красным отмечены повышенные точки риска.

Так, исходя из данных рисунка видно, что в зоне риска специальные скидки в ресторанах. Например, гость сделал заказ на крупную сумму и расплатился наличными деньгами. Сотрудники могут взять деньги и после того, как гость уйдет оформить скидку по данному заказу и тем самым фактически сдать в кассу и отразить в программе меньшую выручку.

Потери по услугам пользования мини-баром, если гость расплатился наличными деньгами. Например, если гость подошел на ресепшен и сразу расплатился за услуги пользования мини-баром. Сотрудники ресепшена могут взять деньги и не сдать их в кассу отеля, не отразив при этом в программе данную выручку.

Коррекции - это перенос недополученной отелем выручки на статью потерь. Существуют следующие причины для коррекций выручки в гостинице:

1. Ошибка персонала. Она может быть как специальная, так и случайная. В зоне риска в данном случае специальная ошибка. То есть, сотрудник может отразить выручку в программе, распечатать чек, гость расплатится наличными, сотрудник проведет коррекции выручки с аргументацией данного действия как ошибку. Здесь нужно понимать, что аналогично действие могло быть и в случае, если гостю распечатали предварительный чек, а он сказал, например, что не использовал данные позиции из мини-бара. Здесь также сотрудник проведет коррекцию выручки.

2. Гость не пользовался. Как уже было сказано в пункте 1 , гость может сказать, что он не пользовался данной услугой. Политика гостиницы в основном такова - «Мы доверяем нашим гостям». Поэтому в данном случае, сотрудники пойдут гостю навстречу и проведут коррекцию выручки. Но так происходит не всегда. В основном это коррекции по выручке мини-бара, редко, какая-либо другая ошибка. Например, в случае со службой питания, если гостю включили чек в его общий счет, а на ресепшене он сказал, что

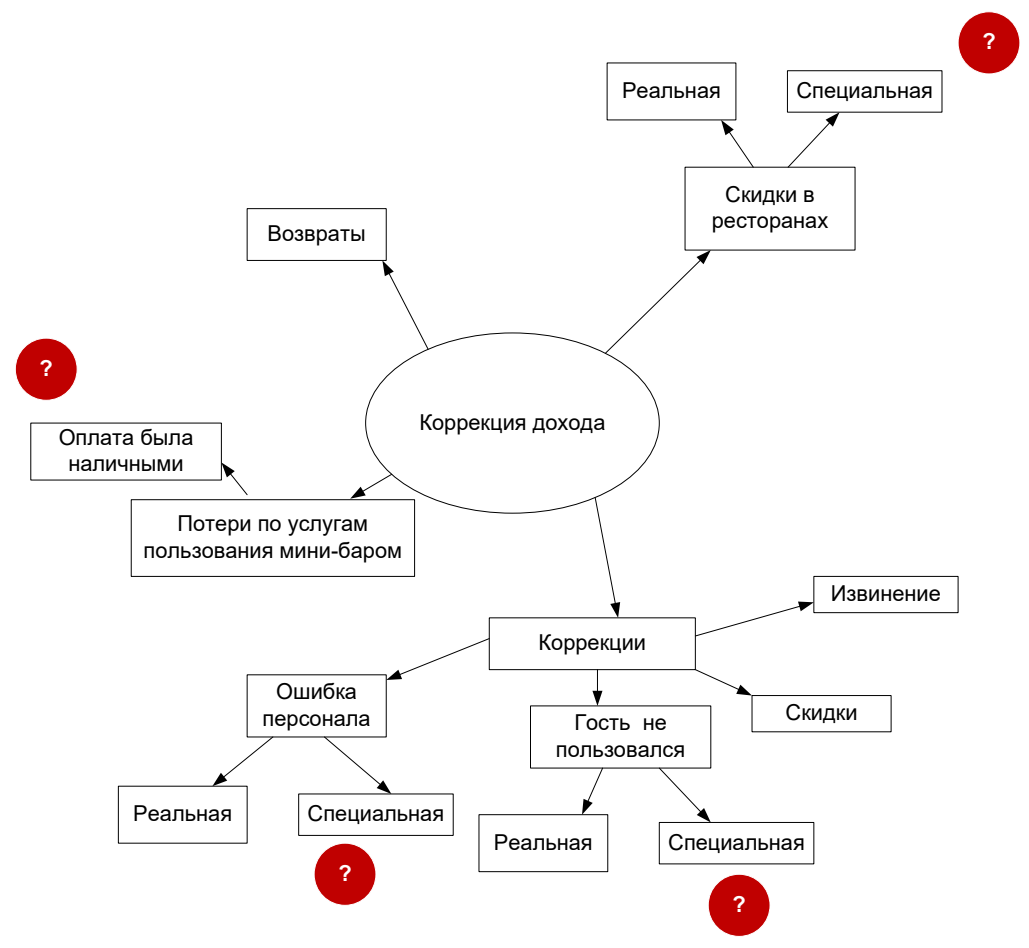

Рисунок 1. Повышенные точки риска 
не пользовался данными услугами, подтверждением будут чеки с подписью, копии которых передаются аудитору на ежедневной основе. Далее разбираться в ситуациях начинают менеджеры подразделений.

3. Скидки. В данном случае указаны скидки, которые делают на ресепшене, если гость, например, забыл скидочную карту и т.д. В таких случаях сотрудники ресепшена предоставляют аудитору объяснительные документы с указанием причины проведения коррекции выручки.

4. Извинение. Вид коррекций выручки, когда гостиница предоставляет гостю что-то в виде извинения. Это может быть какой-то комплимент, например скидка или услуга за счет отеля. Такие виды коррекций выручки могут предоставлять только менеджеры подразделений с подробным описанием ситуации.

По единому стандарту учета для предприятий гостиничной индустрии USALI в качестве отдельных центров дохода могут выделять химчистку, парковку и мини-бар. Это точки продаж, имеющие наибольший риск потери выручки или отражения в программах неполной выручки, взятые в качестве примера для оптимизации системы контроля.

На рисунке 2 представлен процесс взаимодействия сотрудников при отражении выручки за услуги химчистки и ее контроль.

На рисунке 2 видно, что при оказании услуг химчистки между собой взаимодействуют следующие подразделения: ресепшен, отдел химчистки, «сервис в номер», внутренний аудит.

Изначально, гость сообщает на ресепшен о том, что он хочет воспользоваться услугами химчистки. Ресепшен передает информацию в службу химчистки. Гость передает вещи через «сервис в номер» в службу химчистки. После того, как услуга химчистки исполнена, сотрудники данного подразделения передают чек на ресепшен и такой же чек, но уже с вещами, передает в «сервис в номер». Сотрудники «сервис в номер», в свою очередь, отдают вещи и чек гостю. После этого гость подходит на ресепшен и оплачивает услуги. Сотрудник ресепшена отражает выручку и оплату в программе и передает чек аудитору.

На данной схеме процесс отражения выручки является точкой повышенного риска. То есть присутствует риск отражения не всей выручки. Например, гость оплатил услугу химчистки по чеку наличными деньгами. Сотрудник ресепшена оплату взял, но по программе не показал, а свой экземпляр чека выкинул.

По этой схеме особо важным является процесс номер 10 - передача отчета аудитору. Данный отчет, поможет аудитору выявлять услуги, выручка по которым не отражена сотрудниками ресепшена, что сведет к нулю риски не отражения всей выручки за услуги химчистки, ока-

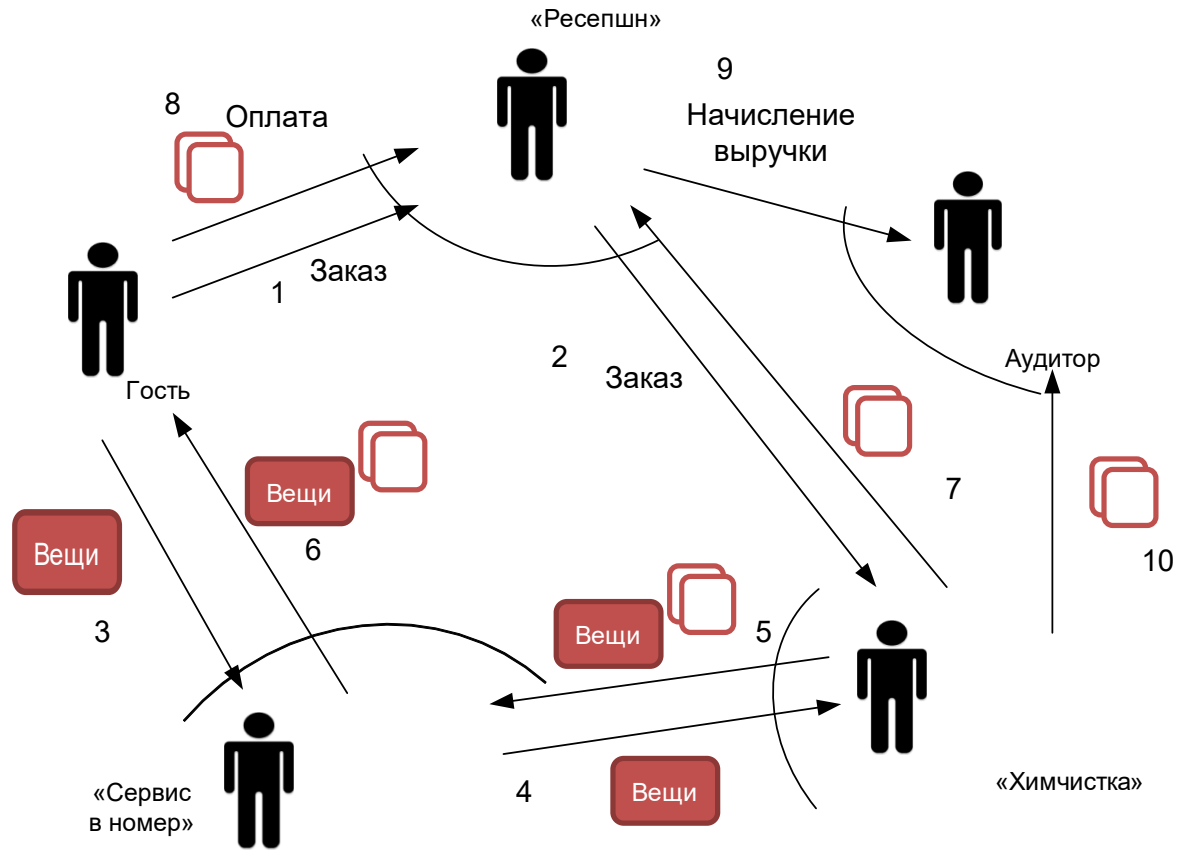

Рисунок 2. Процесс контроля отражения выручки за услуги химчистки 
занные гостям отеля. Многие отели опускают данный процесс, что приводит к получению информации аудитором, которую невозможно достоверно проверить.

В процессе по контролю выручки за услуги химчистки должна присутствовать перекрестная проверка. Т. е. отчеты аудитор будет получать и от сотрудников ресепшена, которые являются материально заинтересованными лицами, и от сотрудников химчистки, которые не являются материально заинтересованными лицами. Другими словами, сотрудникам химчистки необходимо будет на ежедневной основе вести отчет об оказанных услугах, с указанием фамилии и имени гостя, номера комнаты и стоимости услуги. Такой отчет на ежедневной основе будет сдаваться аудитору. Аудитор, получая информацию из различных источников, при сверке данных получит полный объем информации. Таким образом исключится не только специальное не отражение выручки, но и непреднамеренные ошибки, относящиеся к человеческому фактору.

На рисунке 3 представлен процесс отражения выручки за услуги парковки, оказанные гостям отеля и ее контроль.

На рисунке 3 видно, что при въезде на территорию гостиницы на своем автомобиле, гость получает талон с указанием времени заезда у охранника на въезде. После этого он может оставить автомобиль на территории гостиницы. Охранник у камер видеонаблюдения фиксирует номер автомобиля гостя и время заезда. Когда гость решит покинуть гостиницу, ему необходимо подойти на ресепшен для оплаты талона за услугу пользования парковкой отеля. Сотрудник ресепшена указывает на талоне время выезда и ставит печать гостиницы, после этого он отражает выручку и сумму платежа через программу. C оплаченным талоном гость может покинуть гостиницу. Охранник у камер видеонаблюдения должен поставить время выезда машины.

Предлагается в процессе контроля отражения выручки за услуги парковки, оказанные гостям отеля добавить отчет от сотрудников охраны, которые они фиксируют с камер видеонаблюдения время заезда и выезда гостей.

Организация работы в такой форме исключает риск, во-первых,- не отражения всей выручки сотрудником ресепшена. Например, гость оплатил за пять часов наличными, сотрудник ресепшена поставил три часа, при этом деньги за оплаченные клиентом два часа забрал себе и их через программу не отразил. Талон при этом формате работы у гостя чтобы выехать с парковки отеля на своем автомобиле есть, а полной оплаченной им суммы выручки начисленной в

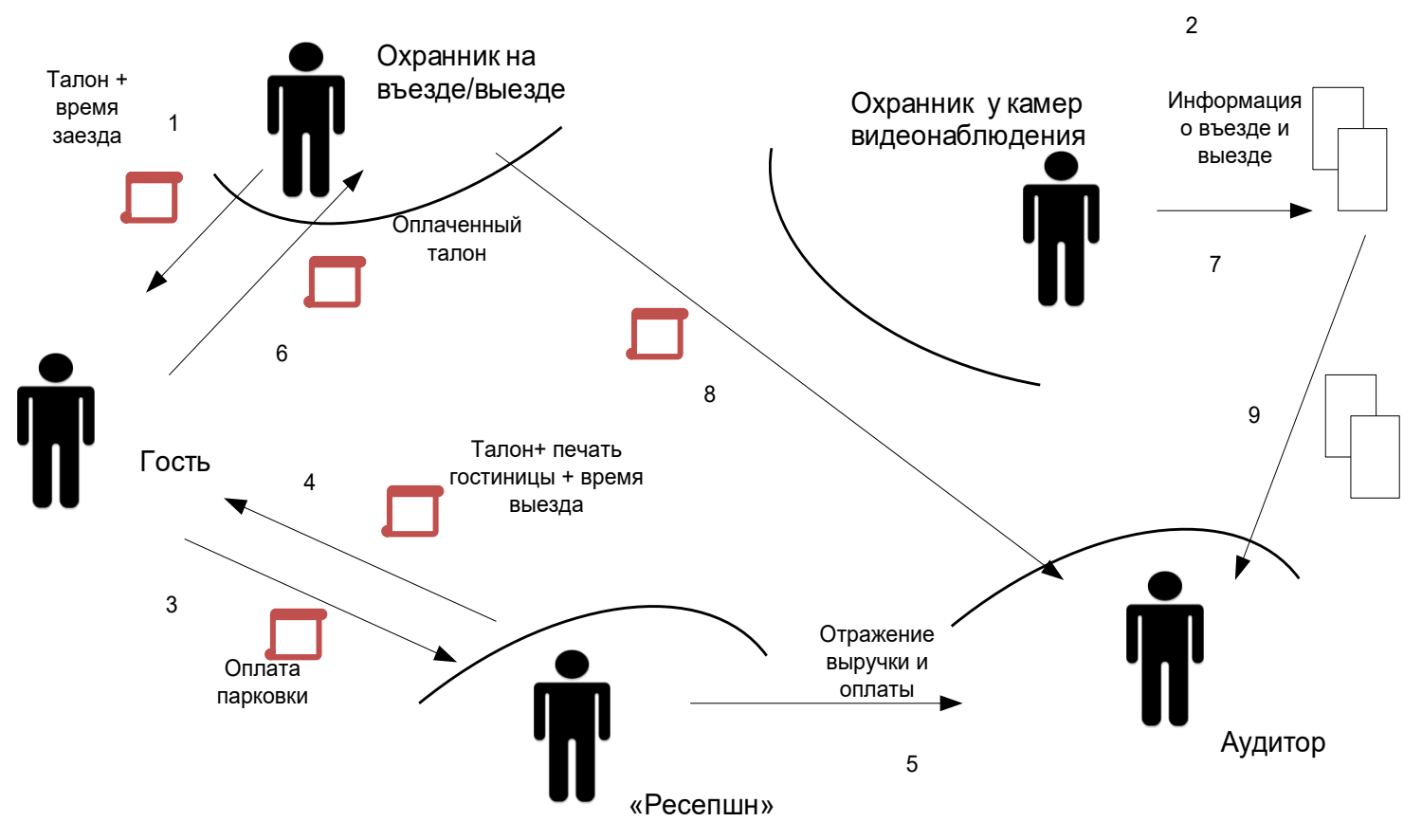

Рисунок 3. Процесса контроля отражения выручки за услуги парковки 
программе нет.

Во-вторых, исключается риск не отражения всей выручки, если гость оплачивает парковку охраннику на въезде.

В отчете должны быть указаны марка и номер автомобиля гостя отеля, его время заезда и выезда, количество часов стоянки автомобиля гостя отеля на парковке. Данный отчет необходимо будет сдавать аудитору на ежедневной основе. Также сотрудники охраны на выезде должны будут отдавать талоны аудитору после каждой смены. При оформлении документа, выписываемого клиенту - талона за услуги пользования парковкой обязательным является пункт - указание номера автомобиля гостя отеля. Данную информацию будет вносить охранник на въезде. Также обязательным должен быть комментарий, с указанием номера автомобиля гостя отеля и количества часов пользования парковкой гостем, в программе при отражении выручки за услуги парковки сотрудниками ресепшен.
Таким образом, аудитор сможет отслеживать и сверять информацию, полученную по данным видеокамер, талонов и в программе, что сведет риски не отражения и занижения выручки за услуги пользования гостями парковкой отеля к минимуму.

На рисунке 4 представлен процесс взаимодействия сотрудников при отражении выручки за мини-бар и ее контроль.

На рисунке 4 видно, что сотрудник отдела, отвечающего за услуги пользования гостями мини-баром, в случае если гость имеет счет в гостинице, начисляет выручку по счету клиента, после чего гость его оплачивает. Если гость выехал из гостиницы, сотрудник отдела, отвечающего за услуги пользования гостями мини-баром, передает информацию на ресепшен. Далее, если у сотрудников ресепшена есть данные гостя, он отправляет гостю запрос о снятии денежных средств с его депозита. В положительном случае начисления по счету гостя за услуги бара будут

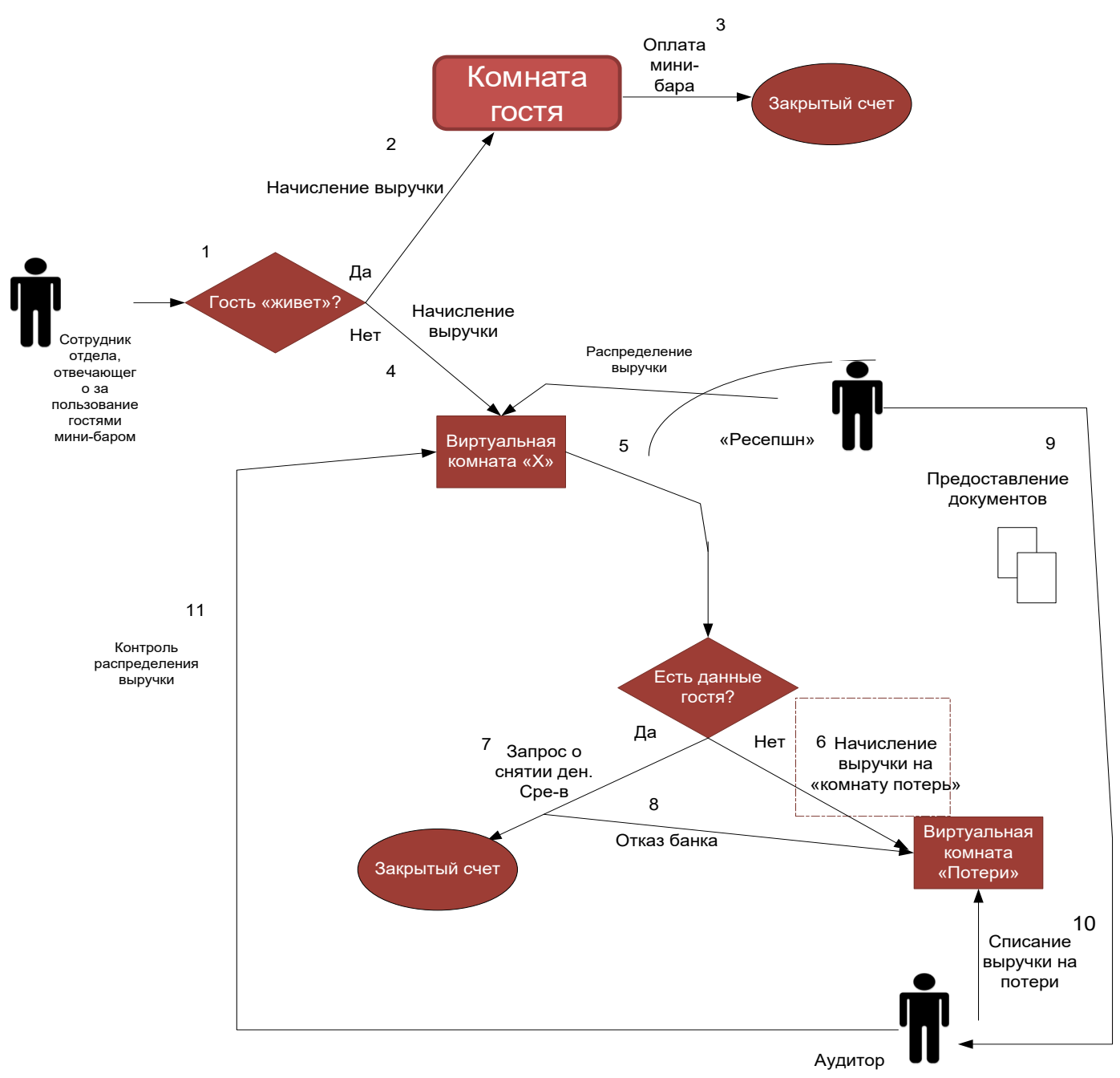

Рисунок 4. Процесс контроля отражения выручки по услугам мини-бара 
оплачены. В случае, если гость откажет в оплате, стоимость позиций по выписанному счету начисляется сотрудниками ресепшена на виртуальную комнату отеля «Потери». Туда же начисляются позиции гостей, по которым данные у ресепшена отсутствуют. Также сотрудники ресепшена предоставляют аудитору документы по гостям, чья выручка начислена на виртуальную комнату «Потери», с объяснением причины для списания.

Риском, который может появиться в данном процессе - аналогично процессу «парковка» и «химчистка» - не отражение всей выручки сотрудниками ресепшена. В данном случае сотрудник ресепшена является материально заинтересованным лицом.

И если не внести в процесс контроля отражения выручки за услуги пользования гостями мини-баром отеля следующий пункт появится большой риск не отражения выручки в полном объеме. А именно, добавить виртуальную комнату, на которой сотрудники отдела, отвечающего за услуги пользования гостями мини-баром, будут отражать выручку, относящуюся к гостям, которые уехали. После этого сотрудники ресепшена будут распределять данную выручку в программе, т.е. это начисления, которые будут оплачены или же данную выручку нужно будет списать на потери.

Аудитор на ежедневной основе будет проверять баланс виртуальной комнаты и отслеживать, чтобы там не было начислений, которые не были вовремя распределены. Все начисления без оплаты также на ежедневной основе отслеживаются.

Данная процедура учета услуг за пользование мини-баром гостями отеля позволят минимизировать риск не отражения всей или частично выручки за пользование мини-баром, так как процедура отражения выручки будет перенесена с материально заинтересованного лица, а именно, сотрудников ресепшена, на материально незаинтересованное лицо, а именно, сотрудников отдела, отвечающего за услуги пользования гостями мини-баром.
В сложившейся сложной экономической ситуации в мире показать точный экономический эффект от внедрения мероприятий невозможно, так как с марта границы России закрыты, а основной источник дохода гостиницы - это иностранцы. Несмотря на карантинные меры, в данный момент отели работают, так как имеет непрерывную деятельность и относятся к организациям, которым с непрерывным производством. На сегодняшний день загрузка гостиницы минимальна. Сравнивать объем выручки в настоящий момент является нецелесообразным. Однако система внутреннего контроля и мероприятия, предложенные автором, не влекут дополнительных финансовых затрат для отеля.

Можно сделать вывод, что благодаря предложенным выше мероприятиям были решены следующие задачи:

- минимизирован риск не отражения всей или частичной выручки по таким источникам доходов, как «химчистка», «парковка» и «мини-бар»;

- повышен контроль за своевременной оплатой отраженной в программе выручки;

- четко разделена ответственность за начисление выручки между сотрудниками в программе по точкам продаж, приведенных в пример.

В заключение проделанной работы можно сказать, что хищения со стороны сотрудников организации, к сожалению, очень распространенная проблема. В настоящее время, когда доходы коммерческих организаций минимальны из-за пандемии, риск недобросовестной деятельности наемных работников очень высок. Причина этого в том числе и снижение доходов сотрудников, так как большинство получает процент от продаж.

Некоторые работодатели не считают работу с хищениями важной, так как сотрудники, как правило, воруют понемногу, однако если предположить, что каждый будет относиться к работе недобросовестно, в целом компания понесет убытки на довольно крупную сумму. Но налаживание внутреннего контроля по средствам введения или изменения операционных процедур.

\section{Библиографический список}

1. UNIFORM SYSTEM OF ACCOUNTS FOR THE LODGING INDUSTRY (USALI) 11th Revised Edition \\ Hospitality Financial and Technology Professionals (HFTP); the Hotel Association of New York City; the Financial Management Committee (FMC) of the American Hotel \& Lodging Association (AHLA) $\backslash \backslash 2014$ year -353 p. 